\title{
Trabalho no hospital: ritmos frenéticos, rotinas entediantes
}

\author{
Claudia Osorio ${ }^{1}$
}

Universidade Federal Fluminense

\begin{abstract}
O artigo apresenta o cotidiano do trabalho realizado nas enfermarias de um hospital geral público na cidade do Rio de Janeiro. A descrição e análise dessa atividade foram construídas em colaboração com os trabalhadores de saúde, através de observação direta, entrevistas abertas e grupos de discussão. A análise focalizou as relações estabelecidas, na equipe de saúde, entre os diversos grupos de trabalhadores, bem como as relações destes com seu trabalho, as cargas de trabalho e a relação entre trabalho prescrito e trabalho real. Observou-se uma grande distância entre o prescrito e o realizado, e uma contradição aguda entre o ideal de trabalho de equipe em prol do paciente e o trabalho real, que resulta fragmentado e realizado em um ambiente de falta de cooperação entre grupos e categorias profissionais, gerando sofrimento para diversos participantes dessa rede de relações.
\end{abstract}

Palavras chave: Processo de trabalho, Carga de trabalho, Trabalho prescrito, Trabalho real, Hospital.

Hospital work: frenzied rhythms, tedious routines

The article presents the infirmaries daily work in a public general hospital in Rio de Janeiro. The activities description and analysis were developed with the health workers participation, by direct observation, open interviews and discussion groups. Aspects of the work process are analyzed, highlighting: the relationships established in the health team, considering the several groups of workers among themselves and with their work, the workloads and the relations between prescribed and real work. The study shows a great distance between the prescribed and the real work, and an acute contradiction between the ideal of a team work developed for the benefit of the patient and the real situation: an environment of lack of cooperation between groups and professional categories, which creates suffering to participants of this net of relationship.

Keywords: Work process, Workload, Prescribed work, Real work, Hospital.

\section{Introdução}

$\mathrm{N}$ a década de 1990, os profissionais do Programa de Saúde do Trabalhador da Secretaria de Estado de Saúde do Rio de Janeiro receberam de um hospital da rede pública uma demanda de apoio e assessoria a seu Núcleo de Saúde do Trabalhador. Uma das preocupações apresentadas dizia respeito ao desgaste sofrido pelo pessoal de enfermagem, que desenvolvia suas atividades no cuidado aos pacientes internados. Considerava-se que essa atividade era muito penosa, com cargas excessivas geradas pela deficiência quantitativa de pessoal. Os exames médicos realizados apontavam alta prevalência de doenças hipertensivas, queixas de cansaço e dores lombares.

Uma primeira análise da solicitação recebida resultou no mapeamento de riscos em alguns ambientes do Hospital (Araújo, 1992) e na análise epidemiológica do sofrimento psíquico vivido pelos servidores, relacionando-o ao processo de trabalho hospitalar (Rego, 1993). Foi avaliado que o pessoal de enfermagem lotado nas enfermarias clínicas apresentava acentuado sofrimento. Os estudos seguintes tiveram como objeto o processo de trabalho hospitalar e suas conexões com processos de subjetivação produzidos no dia-a-dia dessas enfermarias (Santos, 1995; Osorio, 1994). Foram feitas observações e entrevistas que tinham como foco as atividades dos auxiliares de enfermagem e suas relações com aquelas dos demais participantes do atendimento aos pacientes. Observou-se que as queixas da enfermagem vinham de longa data, não tendo deixado de existir quando o quantitativo era maior. 
Colocou-se então a hipótese de que as cargas excessivas fossem resultado da dinâmica institucionalizada de funcionamento, em que a falta de pessoal contribuía para evidenciar problemas que há muito eram ignorados.

Neste artigo são apresentados o desenvolvimento e alguns resultados de um dos estudos acima mencionados (Osorio, 1994). Naquele, buscava-se produzir e identificar modos de superar o sofrimento dos servidores, em especial os do setor clínico de internação, através da construção coletiva do conhecimento acerca dos modos de trabalhar desenvolvidos no Hospital $^{2}$.

São analisadas a organização e as cargas de trabalho e seus desdobramentos na relação que o trabalhador tem com seu trabalho. Por carga de trabalho entendemos as exigências postas aos profissionais pelo processo de trabalho, levando em conta os modos como os próprios trabalhadores as vivenciam. O conceito de carga não tem necessariamente a conotação de peso ou dificuldade: a carga de trabalho pode dar sentido ao trabalho e tanto a sobrecarga, quanto a subcarga podem propiciar desordens somáticas e acidentes, além de eventuais efeitos negativos sobre a produção (Brito, 1991).

Começaremos apresentando os métodos de abordagem adotados, passando a seguir à descrição de vinte e quatro horas vividas nas enfermarias e a algumas análises do trabalho no hospital, buscando a contribuição de diversos autores que desenvolveram o tema. $\mathrm{Na}$ análise da organização do trabalho, destacam-se as defasagens entre o prescrito e o realizado, bem como as cargas mentais e psíquicas da atividade.

A análise da divisão do trabalho e das estratégias adotadas para redução das cargas excessivas sugere que as relações que se tecem nas equipes estão marcadas pela contradição entre o ideal do trabalho solidário em prol do doente e o alto grau de competição entre grupos e categorias profissionais.

\section{A observação das enfermarias}

O setor clínico de internação do Hospital estudado dividia-se em duas alas, localizadas no mesmo andar de um velho prédio, cada uma com um posto de enfermagem. De um lado estavam as enfermarias femininas e de outro as masculinas. Aí eram internados pacientes de pneumologia, nefrologia, cardiologia, oncologia, hematologia e clínica médica. Durante três semanas foram observadas as atividades de atendimento aos pacientes, realizadas entrevistas com a enfermagem e consultados prontuários, escalas de plantão, livros de ocorrência, rotinas e informações afixadas nas paredes do posto de enfermagem. A seguir, foram entrevistados assistentes sociais, nutricionistas e médicos, bem como a chefia de enfermagem, a Comissão de Controle da Infecção Hospitalar (CCIH) e a direção do hospital. $\mathrm{O}$ texto originado descrevia em detalhes as atividades e foi apresentado à enfermagem, propondo-se a busca conjunta de alternativas para o trabalho cotidiano.

Seguindo uma metodologia participativa, convidamos os profissionais de enfermagem para uma reunião em que o processo de trabalho descrito, as dificuldades apontadas e suas possíveis soluções seriam tema de debate. Ao convidá-los, ouvimos ponderações de que "isto não vai dar certo"; alegava-se que as pessoas não poderiam abandonar o trabalho para a reunião e que aqueles que não estivessem de plantão não poderiam comparecer por falta de dinheiro para passagem, de alguém com quem deixar os filhos, tarefas domésticas a cumprir, cansaço, outro emprego e falta de crédito nos resultados. Dizia-se que "são sempre as mesmas

\footnotetext{
2 Embora a dissertação de mestrado que gerou este artigo tenha sido apresentada em 1994, acreditamos que hoje vivemos situação bastante semelhante à que o leitor irá se deparar.
} 
pessoas que comparecem enquanto as demais nem se importam, isso não é justo e não leva a nada". Insistimos, mas ninguém compareceu. Provocamos então, indo a cada plantão, reuniões curtas, que chamamos "grupos-relâmpago" (Osorio, 1994). Foram postas em discussão a fidelidade do texto produzido ao cotidiano nas enfermarias e sugestões de mudança a fim de solucionar problemas. Autorizados pela enfermagem, discutimos o texto final com a chefia de enfermagem. $\mathrm{O}$ material que se segue foi construído nesse processo de observações e debates.

\section{As enfermarias}

Havia no setor 26 leitos ocupados na ala feminina e outros 26 na masculina. Além desses, havia leitos desativados devido à insuficiência de enfermeiros e auxiliares, o que vinha se agravando com a aposentadoria de muitos servidores. Os pacientes, na sua maioria, eram idosos eou tinham pouca autonomia, necessitando banho no leito, ajuda para alimentação e observação constante. Havia, em cada ala, um enfermeiro pela manhã, outro à tarde, dois ou três auxiliares de enfermagem (AE) e um auxiliar de serviços operacionais (AOSD) ${ }^{3}$. A maior parte do serviço burocrático e de comunicação com outros setores era feito pela secretária, contratada por uma empresa na função de servente. $O$ trabalho da enfermagem com os pacientes mais graves era em parte aliviado pela presença de acompanhantes. Mas essa organização gerava outra sobrecarga, devida à demanda de atenção dos próprios acompanhantes e aos conflitos quanto às tarefas que lhes deveriam ser repassadas.

Enfermeiros e auxiliares queixavam-se de cansaço, lombalgias e hipertensão arterial. Existiam freqüentes faltas e licenças por agravos à saúde, com aumento da carga de trabalho para os que compareciam ao trabalho. Os trabalhadores de outros setores não aceitavam facilmente substituir colegas deste setor, considerado o de maior carga. A enfermeira chefe visitava diariamente o posto e, em um determinado dia, constatou que na ala masculina a equipe de plantão consistia em um único auxiliar de enfermagem, que havia chegado queixando-se de "bursite" e de não ter dormido bem por causa da dor. A chefe resolveu o problema, de forma centralizada e solitária, deslocando um AE do setor de siálise e assumindo ela mesma a organização das prescrições.

\section{4 horas de cuidados prestados}

No primeiro horário da manhã (às 7 horas) realizava-se a passagem do plantão, com o relato de uma equipe a outra das principais ocorrências do período noturno, de modo pouco formal, em cerca de 20 minutos. Falava-se sobre os pacientes mais graves e sobre as situações consideradas fora da rotina. A conferência do material e a leitura do livro de plantão, que deveriam ser feitas pelo enfermeiro, nem sempre eram realizadas. No ritmo apressado essas eram tomadas como atividades "menos urgentes". Os atrasos eram constantes, principalmente na ala masculina. Eles suscitavam ansiedade e irritação em quem esperava substituição, mas também provocavam sentimentos de solidariedade: "acho que ele não consegue mais despertar como antes só de pensar em enfrentar tudo de novo".

O desjejum dos pacientes deveria ser servido entre 7 e 8 horas. $O$ ritmo de trabalho era frenético no período das 8 às 11 horas, quando se concentravam a quase totalidade das

3 Essa função encontra-se em extinção, mas ainda restam servidores que foram contratados dessa forma. 
tarefas. Por volta das 8 horas o enfermeiro ${ }^{4}$ percorria os leitos e cumprimentava os pacientes, inteirando-se da situação de cada um; avaliava os cuidados que cada um necessitava, os que estavam mais ou menos prostrados, ouvia reclamações e queixas; anotava os banhos de leito, cadeira ou ajuda. Os banhos de leito eram considerados tarefas pesadas. Cada banho demandava cerca de vinte minutos, sendo em geral seguido de curativos, já que diversos pacientes apresentavam escaras. Num dia observado foram registrados, na ala feminina, seis banhos no leito, um de cadeira e dois de ajuda. Dentre aqueles de leito, dois eram em mulheres idosas, obesas, em estado de extrema prostração, prestados por duas AEs que se queixavam de dores nas costas. Uma das pacientes gritava sempre que moviam seu corpo e a expressão facial das auxiliares revelava a tristeza e o mal-estar que isso provocava. Os comentários no corredor, feitos pela equipe médica, indicavam que "a ortopedia havia sido chamada há um mês e não vinha ver a paciente". Outras pacientes, infectadas por microorganismos resistentes aos antibióticos habituais, implicavam risco de contaminação ocupacional. Foram usados luvas e capotes leves, usando-se capotes maiores e máscaras para as contaminadas por stafilococos. Dois dos banhos no leito foram feitos por um AOSD auxiliado por uma acompanhante, que auxiliou também o banho da paciente do leito vizinho. Dentre nove banhos de leito realizados na ala masculina, três eram de pacientes soropositivos para AIDS. No último foram retiradas as luvas no momento de recolocar a sonda vesical no paciente. Os auxiliares queixavam-se de alergia às máscaras. Após os banhos eram trocados os lençóis. Devido à escassez de roupa, recorria-se, por vezes, ao uso de lençóis pediátricos, o que demandava mais tempo e maior esforço físico. Segundo médicos antigos no hospital, "os lençóis sumiam na passagem pela lavanderia". Essas tarefas encerravam-se por volta de 10 ou 11 horas da manhã.

Durante o período dos banhos, o enfermeiro atendia a situações de maior complexidade, providenciava materiais que faltavam e auxiliava médicos quando solicitado. Os enfermeiros comentaram a grande responsabilidade que lhes era atribuída, acompanhada de dificuldades pela falta de pessoal. Os auxiliares eram poucos, a maioria mulheres com mais de 40 anos, com dificuldades para realizar as tarefas necessárias. Essa situação gerava tensão e cansaço. Ainda se agravava, segundo os relatos, com o hábito da equipe médica de tudo solicitar ao enfermeiro, mesmo materiais que se encontravam ao alcance de toda a equipe, e não sob sua guarda. Essa questão originava conflitos: parte dos enfermeiros e auxiliares fazia a crítica aqui apresentada, mas outros consideravam o posto e tudo que ele continha como território da equipe de enfermagem, considerando qualquer interferência nesse espaço como intromissão.

Durante o período da manhã, preferencialmente após os banhos, os médicos visitavam os pacientes; os internos de medicina anotavam as prescrições e faziam pedidos de exames, que seriam encaminhados pela secretaria aos destinos devidos. Os médicos circulavam com a atenção dirigida a seus pacientes. Ao aproximarem-se do balcão do posto de enfermagem, para leitura e anotações em prontuários, nem sempre se davam conta da presença de outros profissionais não médicos. Em um dado momento, uma enfermeira interpelou um médico, seu companheiro na direção do centro de estudos: "Não fala mais comigo...", iniciando um diálogo amigável. De modo geral, os diálogos diziam respeito apenas às tarefas assistenciais. Pessoas estranhas que se encontrassem no posto, nos corredores ou enfermarias (com no caso das pesquisadoras) raramente eram percebidas e cumprimentadas.

Após o banho era iniciada a limpeza, feita por funcionários de uma empresa contratada. A partir das 11 horas o ambiente se transformava, diminuindo o ritmo intenso observado desde as 8 horas. $\mathrm{O}$ almoço era servido e às 13 horas o plantão era então passado ao enfermeiro da tarde. 
Entre 13 e 15 horas eram feitas tarefas não realizadas pela manhã "por falta de tempo ou qualquer outro motivo". Após esse horário iniciava-se o período de visita dos familiares.

O plantão da noite iniciava-se às 19 horas, com a passagem dos casos da equipe diurna para a noturna. Aí também existiam queixas de atraso, implicando a extensão do horário da equipe do dia. Em geral apenas um funcionário (enfermeiro ou auxiliar) aguardava o primeiro a chegar para o plantão seguinte. Após diversas tentativas de solução administrativa, o problema dos atrasos foi considerado sem solução. No período da noite não havia banhos de rotina e os auxiliares estavam menos atarefados. Mesmo assim, foi adotado procedimento idêntico ao da manhã: a tarefa de preparo da medicação foi dividida, fazendo um a oral, outro a injetável mais os soros. A ceia era servida ao mesmo tempo em que iam sendo feitas medicações, nebulizações, aspirações e verificações de pressão arterial e temperatura. A administração da ceia a um paciente grave durou 20 minutos. A administração de cuidados e medicação foi feita por um AE, enquanto outro fazia algumas trocas de roupas e lençóis. Ele levou 20 minutos para trocar, sozinho, a roupa de uma paciente prostrada e queixou-se de problemas na coluna. A falta de material era freqüente nos plantões noturnos, quando a farmácia e o almoxarifado estavam fechados, gerando ansiedade nos auxiliares. Outro motivo de ansiedade era a manutenção precária dos equipamentos, como a ausência de grades nos leitos, o que já havia propiciado acidentes.

No trabalho diurno existiam poucos momentos de descanso. Eles ocorriam no horário da visita dos familiares, ao final do plantão, ou nas fugas ocasionais do andar. As refeições eram corridas, para possibilitar a saída do colega, uma vez que o horário de funcionamento do refeitório era limitado. No período noturno, em especial após a meia-noite, havia revezamento para descanso de três em três horas, ficando sempre um AE no posto.

A equipe de enfermagem trabalhava no limite máximo de suas possibilidades: qualquer contratempo gerava o caos. $\mathrm{O}$ agravamento súbito de um paciente fazia com que outros atendimentos fossem feitos de forma precária. Comentava-se que ninguém poderia ficar doente, tirar licença ou férias, sob pena de sobrecarregar violentamente os colegas. Foram observadas pessoas trabalhando sob o efeito de injeções sedativas da dor lombar, com fortes gripes e com férias vencidas. Alguns auxiliares referiram-se com críticas à "folga prêmio", artifício que visava reduzir o número de licenças médicas, premiando aqueles que não faltassem nem pedissem licença. Havia acusações de favoritismos na equipe. Confrontados, nessa época, com a possibilidade de reabertura de leitos desativados, os auxiliares reagiram comentando que teriam que "escolher entre dar banho, comida ou remédios". De acordo com os relatos, essa situação já ocorrera, a escolha tendo recaído na medicação: vários pacientes graves não se alimentaram naquele plantão. Existiam queixas da equipe médica de que, com alguma freqüência, os pacientes deixavam de receber a medicação prescrita. Essa queixa era veementemente contestada pela enfermeira chefe. Os médicos insistiam, usando como confirmação depoimentos de pacientes. Não parecia difícil, a quem observava o ritmo intenso do trabalho, sua fragmentação e o estado de ânimo da enfermagem, imaginar que erros ocorressem com freqüência. Ficava claro que a equipe médica atribuía tais erros à falta de responsabilidade ou empenho da enfermagem, em uma sempre presente busca de culpados pelo caos vigente.

\section{O espaço e as condições de trabalho}

As enfermarias tinham janelas amplas, voltadas para áreas verdes. Desembocavam num longo corredor com uma janela ao fundo. No lado oposto às enfermarias, pouco ventilado, estavam os postos de enfermagem, os banheiros de pacientes, dois quartos 
individuais e os expurgos (local onde são lavados equipamentos que dispensam esterilização). Em frente a cada um dos postos havia um ventilador barulhento, numa tentativa mal sucedida de minorar o calor. $O$ espaço de circulação nas enfermarias era restrito: quando eram utilizados biombos para isolamento visual de algum leito, eles ficavam encostados aos leitos vizinhos. Nos corredores, a circulação era prejudicada pela permanência de macas, carrinhos e aparelhos. Os banheiros eram distantes dos leitos, gerando maior carga no atendimento àqueles com dificuldades de locomoção.

A enfermagem da ala feminina dispunha de um repouso onde o pessoal guardava seus pertences, fazia lanches rápidos e descansava durante o plantão noturno. Tratava-se de um espaço exíguo, com beliches e armários de metal, sem janelas ou qualquer outra ventilação. Era aí que, quando necessário, os enfermeiros conversavam reservadamente com os auxiliares. A entrevista com um enfermeiro, com uma hora de duração, foi realizada nesse espaço. Sentados durante todo o tempo em camas-beliches, ao final estávamos bastante doloridos! Todos afirmaram que as precárias instalações eram conquista de luta, obtidas por ocasião de campanha para eleição da direção e eram "melhor que nada". Antes já haviam dormido muitas vezes no chão ou em cima de mesas, quando o cansaço se tornava insuportável. $\mathrm{Na}$ ala masculina existia outro repouso menos precário. Existiam, no andar, espaços ociosos que haviam sido oficialmente requisitados para esse fim. Um desses, com uma ampla janela, boa ventilação e banheiro privativo, ao lado do serviço de diálise, estaria reservado para futura ampliação desse serviço.

Os enfermeiros eram responsáveis pela autorização da presença de acompanhantes para pacientes graves, mas não dispunham de salas de consulta em que pudessem orientar os pacientes e seus acompanhantes quanto a sua estada na enfermaria. As entrevistas ocorriam ao lado do leito do paciente, no corredor ou no balcão do posto de enfermagem.

Os plantonistas da enfermagem faziam, no refeitório, uma refeição e um lanche por plantão de 12 horas. Caso algum deles decidisse tomar o desjejum, não teria direito ao lanche da tarde. Essa determinação não considerava a distância a percorrer de casa ao trabalho. Caso resolvessem trazer um lanche de casa, não teriam lugar adequado para guardá-lo, nem para consumi-lo: lanchavam sentados nas camas do quarto de repouso ou no posto da UI (para onde haviam "escapado"). As refeições eram servidas num horário restrito e a equipe queixava-se de não poder "reservar" a refeição, como faziam as unidades fechadas, quando "o plantão está pegando fogo". Beber água também parecia ser uma tarefa árdua. Existiam bebedouros nos corredores, mas eram considerados sujos e pouco confiáveis. As garrafas de água eram distribuídas apenas aos pacientes, tampadas com plásticos que, uma vez retirados, não aderiam novamente. Ir ao refeitório para beber água obrigaria a interromper as tarefas e o refeitório era fechado às 22 horas.

Os postos de enfermagem eram pequenos, com bancadas de trabalho também pequenas. Toda sua área, a exceção do depósito de roupa, estava exposta à visão de quem circulava no corredor. Os banheiros exigiam verdadeiro contorcionismo para entrar, fechar a porta e fazer uso das instalações sanitárias.

Para as demais categorias profissionais, as condições pareciam um pouco menos precárias, dada a liberdade maior de horários e de organização das tarefas, com menos divisões hierárquicas internas e menor tempo total de permanência no local de trabalho.

O serviços social dispunha de uma pequena sala para entrevistas, além de instalações no prédio vizinho, onde ficava o ambulatório. As assistentes sociais não dispunham de telefone externo próximo às enfermarias, o que as fazia percorrer muitos quilômetros por dia: "isso mantém a forma delas, não precisa dieta, vai e volta, vai e volta, mais de 30 vezes... prá convocar família, chamar empregador, tentar recursos... fora a alta, que a gente acaba informando à família. E vai e vem, vai e vem, 365 dias do ano". De acordo com os relatos, "as condições de trabalho das assistentes sociais no segundo andar são terriveis: uma cadeira e um banquinho para 
quatro [profissionais], uma sala que é um pedaço do corredor para quatro, e todas as famílias de todos os pacientes do segundo andar. Fora a assistente social do terceiro andar, que também desce quando precisa de privacidade [já que não há sala de entrevista no andar cirúrgico]".

A equipe médica dispunha de quatro salas com amplas janelas voltadas para áreas verdes, sendo uma para trabalho individual e reuniões, uma para a chefia e duas para consultas e exames físicos. Os médicos anestesistas, vinculados à clínica cirúrgica, que funcionava no andar superior, dispunham de uma ampla sala no andar clínico, quase sempre fechada.

A distribuição de espaço dava, portanto, indicações claras da hierarquia produzida pela divisão do trabalho e pelo prestígio alcançado por cada grupo profissional. A enfermagem, responsável pela execução, recebia espaços menores e menos ventilados, não sendo contemplada com alguns confortos, como consultórios e espaços para reuniões. Os grupos intermediários, como os assistentes sociais, estavam no meio termo na distribuição dos espaços. A falta de espaço para distribuição eqüitativa às diversas categorias poderia gerar a criação de espaços compartilhados, multiprofissionais. Questionados, nenhum dos grupos considerou tal solução viável.

\section{A organização do trabalho: o trabalho prescrito e o trabalho real}

A psicologia ergonômica define a tarefa como aquilo que deve ser feito e a atividade como aquilo que se faz (Leplat \& Hoc, 1983). A atividade é entendida como a intenção momentânea do operador, protegida de outras intenções que competem com ela. $\mathrm{Na}$ distância existente entre o prescrito e o realizado é que se pode produzir o sentido do trabalho, um trabalho de que fazem parte os conflitos, as dúvidas, as paixões, e não um trabalho concebido como uma seqüência de gestos operacionais regidos por uma inteligência desencarnada.

O trabalho aqui descrito, embora fruto de uma observação local e datada, pode ser considerado característico do cotidiano de muitos hospitais. De acordo com o prescrito, o trabalho nas enfermarias tem por finalidade o tratamento do paciente até que este possa ser realizado no domicílio. $\mathrm{O}$ tratamento é dividido e atribuído a diversas categorias profissionais, contando cada uma com uma chefia, que é ocupada por profissional da mesma formação, subordinados todos à divisão médica. Os médicos prescrevem os procedimentos de diagnóstico e o tratamento, determinando o trajeto que o paciente desenvolverá dentro do hospital. As decisões quanto à terapêutica prescrita são inteiramente suas. Questões administrativas, tais como haver ou não seringas suficientes para a administração dos medicamentos do dia, não constituem preocupação dos médicos, mas sim dos enfermeiros. Os nutricionistas prescrevem as dietas com base no que os médicos solicitam; fazem a dosagem e acompanham o preparo de alimentação enteral; têm seus vínculos empregatícios com uma firma contratada. O serviço de nutrição do próprio hospital é responsável pelo controle e pela fiscalização do trabalho dessa empresa, pelo atendimento ambulatorial e pela administração do setor. Os assistentes sociais atuam nas relações entre o paciente, sua família e seu mundo, visando sanar as dificuldades que a situação de internação pode trazer à vida social do paciente. $\mathrm{O}$ enfermeiro organiza o posto de enfermagem, determina a divisão das tarefas entre os auxiliares e realiza alguns procedimentos terapêuticos. As secretárias auxiliam na organização de prontuários, marcação de exames, transcrição e encaminhamento das prescrições ao setor de farmácia. Existem ainda os maqueiros terceirizados, contratados como serventes e sem formação na área de saúde. 
A equipe de enfermagem tem horários de trabalho bem definidos, o que não ocorre com os demais profissionais. A equipe médica é a que sofre menor controle de horário, devendo trabalhar 20 horas semanais. Os enfermeiros do período diurno são diaristas: entram às 7 horas e são rendidos às 13 horas por outra turma, que trabalha até as 19 horas. Durante o dia, há um enfermeiro em cada posto. Durante a noite, a quantidade de enfermeiros é menor e eles, assim como os auxiliares, são plantonistas. São três equipes de plantão noturno, cada uma com um supervisor e pelo menos um enfermeiro por andar. Os AEs estão em contato direto com os pacientes, administrando a terapêutica prescrita pelo médico e organizada pelo enfermeiro. Aos operacionais (AOSDs) cabe um papel de apoio. Os auxiliares estão distribuídos em três equipes que fazem plantões de 12 horas seguidas por 60 horas de descanso (12/60), tanto durante o dia, quanto durante a noite e estão subordinados ao enfermeiro da ala ou do setor onde atuam.

A organização do trabalho prescrita, de modo mais ou menos formalizado, define a divisão do trabalho, de acordo com o posto de trabalho ou a função de cada um. Essa divisão, não sendo apenas técnica, distribui desigualmente as tarefas tanto do ponto de vista das quantidades, como das qualidades. Aos socialmente mais favorecidos, são atribuídas as tarefas qualificadas, em geral menos arriscadas e menos danosas à saúde; aos menos favorecidos, aquelas que exigem menor qualificação e, em geral, oferecem maiores riscos de acidentes e doenças.

A divisão do trabalho na equipe de enfermagem é clara. Os enfermeiros coordenam, orientam e supervisionam a assistência aos pacientes, que consiste na administração das prescrições médicas e dos cuidados gerais. Executam procedimentos de maior complexidade, muitos dos quais podem ser realizados pela equipe médica. A maior parte das tarefas, principalmente as que exigem grande esforço físico e pouco preparo técnico, são executadas pelos auxiliares. Há uma bem estruturada justificativa técnica que torna determinadas tarefas privativas do enfermeiro ou do auxiliar de enfermagem. Do ponto de vista técnico, nada impediria que cada um se ocupasse de tarefas menos complexas que aquelas privativas da função; mas, segundo os comentários dos auxiliares, é raro que os enfermeiros auxiliem nos banhos e outras tarefas que representam grande carga - "é ruim eles pegarem no pesado, heim!". Já entre os AEs e os AOSDs, embora as normas estabeleçam diferenças, elas pouco aparecem.

A leitura do livro de ocorrências, a passagem de plantão e a visita aos pacientes são atividades importantes para o planejamento do trabalho, mas muitas vezes "por falta de tempo" não são cumpridas. Dessa forma, o trabalho do enfermeiro, e mesmo da sua equipe, perde parte do significado, passando a ser desenvolvido de modo mecânico ou emergencial. As anotações da enfermagem e da equipe médica sobre a evolução dos pacientes e as prescrições dos médicos são vias de comunicação que quase nunca podiam ser utilizadas satisfatoriamente. Também em função da "falta de tempo" não há leitura dos prontuários por parte da enfermagem. Pode-se observar mais claramente a importância da participação do enfermeiro, nas visitas aos doentes e na leitura e no uso dos prontuários, quando comparamos as enfermarias com as unidades fechadas, onde essas tarefas são habitualmente observadas.

Após receber o plantão e se desembaraçar das primeiras tarefas, o enfermeiro organizava as prescrições, anotando nas papeletas o horário de cada medicamento ou procedimento. O preparo da medicação era tarefa dos auxiliares, a ser feita após o banho e a arrumação dos leitos. Os itens da medicação - frascos de soro, ampolas e comprimidos - eram separados, preparados e arrumados em bandejas com divisões; o preparo do soro implicava na confecção de rótulos nos quais constavam o número do leito do paciente, o conteúdo do frasco e a etapa correspondente. Essa era uma tarefa atribuída ao AE, mas com a carência de pessoal passava a ser desenvolvida também por AOSDs. Os sinais vitais deveriam ser verificados pelos $\mathrm{AEs}$. Cada $\mathrm{AE}$ deveria ficar responsável por um certo número de pacientes. 
Na prática, os auxiliares parcelavam a tarefa: um preenchia rótulos, outro separava comprimidos etc. Explicavam que da forma prescrita não haveria tempo suficiente para todas as tarefas. Assim, o tempo de preparação dos medicamentos era reduzido, mas o trabalho perdia muito do significado que poderia ter com o atendimento integral a cada paciente por um mesmo auxiliar. Perdia-se a possibilidade de conhecimento do caso, da forma escolhida de tratamento, de revisão e controle pela compreensão do processo como um todo. Esse modo de organizar o trabalho aumentava o risco de falhas tais como uma medicação eventualmente esquecida ou a inobservância de um frasco soro que acaba. Num dado momento um médico reclamou ao enfermeiro que sua paciente estava recebendo um soro diferente do prescrito. $O$ enfermeiro se constituía no alvo preferencial para cobranças. Mas todos, e também ele, ficavam parcialmente protegidos pelo parcelamento e pelas más condições gerais do trabalho. Diversas possibilidades de colaboração e participação eram anuladas. Os auxiliares perdiam a possibilidade de opinar sobre o trabalho desenvolvido e sobre a assistência prestada.

A informação acerca das rotinas foi fornecida pelos enfermeiros de maneira precisa, não havendo, nos depoimentos, dúvidas sobre o que deveria ser feito, embora existissem poucas rotinas escritas a serem observadas. Existe uma rígida separação, no trabalho prescrito, entre concepção e execução, o que leva a uma concentração do poder nas mãos dos responsáveis pelo planejamento. Mas a precariedade geral subverte esta ordem. Temos ao final uma falta generalizada de poder ou de potência. Esse esquema, que pode ter aspectos defensivos, era apontado como fonte de insatisfação. Muitos se queixavam por "não poder dar maior atenção a cada doente", de não haver "tempo de dar assistência emocional ao doente"; dizendo ainda que "se ocorre um agravamento, é preciso escolher entre dar comida ou remédio".

Nos debates feitos em pequenos grupos, alguns enfermeiros discordaram da afirmativa, oriunda das entrevistas com a hierarquia, de que aos AEs estivesse atribuída a simples execução, afirmando que o trabalho daquele segmento implicava no uso de significativo conhecimento técnico, sendo o profissional responsável pelo que faz. Ele seria capaz inclusive de questionar prescrições médicas, o que ocorria "com alguma freqüência"; poderia, nesse caso, dirigir-se ao enfermeiro ou, na ausência deste, diretamente ao médico. Parece haver uma desvalorização, por parte do discurso oficial, de um trabalho que é mais intelectual do que se quer reconhecer. A favor da visão da enfermagem, há a queixa médica de "boicote", de que "a enfermagem é cruel..." e que "voa muito". Ou seja, no trabalho real, a possibilidade de interferência da enfermagem aparece na forma de recusas a realizar mais que o prescrito ou mesmo o prescrito. Os auxiliares demonstravam, pela falta, o valor que tem o seu trabalho.

Outras defasagens podem ser observadas, por exemplo, nas diferentes orientações sobre como lidar com os riscos biológicos. O banho no leito, seguido de curativos e troca de sondas, é um momento que oferece riscos de contaminação. Entre um e outro banho nem sempre os capotes eram trocados; questionados, os auxiliares alegaram que os pacientes apresentavam o mesmo tipo de infecção e que não haveria tempo para trocar as roupas a cada banho prestado. Um enfermeiro afirmou que o risco de doenças infecto-contagiosas era grande, e "como não são tomadas providências pelas hierarquias superiores", sua orientação aos auxiliares era de "não se aproximarem muito dos doentes que representam risco de contaminação" (nesse caso estavam os pacientes HIV positivos). Esses tipos de reações extremas às dificuldades e de medos produzidos no processo de trabalho (abandono dos pacientes) não são considerados freqüentes e dão a dimensão dos sentimentos que atravessavam a equipe.

Um acontecimento revelador do que pode ocorrer, como conseqüência de rotinas fragmentadas ou não cumpridas, está no "sumiço" de pacientes da enfermaria. Durante a observação das atividades, ouvimos um relato de um fato curioso: uma família teria procurado seu parente no horário da visita e, tendo encontrado o leito ocupado por outra pessoa, procurou informações com um auxiliar. Este não sabia informar e o esclarecimento foi 
dado por um servente: o paciente havia sido transferido para o andar cirúrgico. Ao buscar uma melhor compreensão do acontecimento obtivemos as seguintes explicações: "alguns pacientes levantam e saem, na portaria não são parados e vão embora"; "os pacientes são levados para exames", "têm uma licença social", "são transferidos para outros setores do hospital ou para outras unidades e a enfermagem não anota imediatamente a saída". Assoberbado por muitas tarefas, o enfermeiro deixa as anotações de prontuário "para uma hora mais calma". Assim, nem todos da equipe ficam informados e não podem responder aos questionamentos. $\mathrm{Ou}$ ainda, como as rotinas prescritas são muito longas e burocratizadas, as providências são tomadas informalmente, aproveitando os contatos pessoais e a boa vontade de um ou outro.

O relacionamento entre os membros da equipe multiprofissional de saúde foi descrito como "cordial, mas com problemas". A distribuição das tarefas é desigual tanto no tempo, quanto na divisão entre os diversos profissionais. A tão propalada equipe de saúde parece ser uma colcha de retalhos mal costurada.

As relações com os médicos são marcadas hierarquicamente. enfermeiros referiam-se, de forma crítica, a uma relação de subordinação que ultrapassava claramente a divisão técnica do trabalho. Ao mesmo tempo, a enfermeira chefe fez questão de afirmar sua autonomia dizendo que "em outros lugares isso até deve acontecer, aqui não, a enfermagem aqui não se subordina ao médico".

O serviço de nutrição foi considerado, pela enfermagem, essencial na rotina do setor. Foram relatadas visitas pela manhã e na hora do almoço a fim de verificar, junto aos pacientes, a aceitação das prescrições dietéticas. Entre esses dois grupos existiam conflitos, com a explicitação de críticas relativas a efeitos da diminuição do quadro de pessoal, como um distanciamento do acompanhamento ao paciente e da interação com a enfermagem, além da passagem de tarefas do primeiro para o segundo grupo. Um exemplo pode ser o dos esquemas de alimentação enteral. Foi relatado pelos nutricionistas que "passar sonda para alimentação foi, durante algum tempo, tarefa da nutrição, mas com a redução do quadro da nutrição, essa tarefa passou a caber a enfermeiros". Houve época em que "para ajudar, os nutricionistas passavam as sondas e auxiliavam na administração da enteral, mas isso passou a ser visto como obrigação da nutrição, e não é". "Quando o trabalho aumentava e essa ajuda não era possivel, a enfermagem se recusava a passar as sondas e os pacientes ficavam sem alimentação". Existiam queixas dos nutricionistas quanto ao acompanhamento feito pela enfermagem: "tem que correr bem devagar, e eles apressam para não ter que ficar tomando conta"; "tem que lavar a sonda a cada esquema, e isso nem sempre é feito, ai entope". Um outro exemplo de conflito está na relação entre médicos e nutricionistas. Segundo estes, alguns médicos, "especialmente os mais idosos", "não gostam que a prescrição de dieta seja feita pelo nutricionista".

Com a falta de pessoal e o excesso de trabalho, algumas tarefas eram empurradas de um lado para outro. A argumentação para reservar a tarefa para si ou repassá-la a outrem era freqüentemente da ordem da técnica, da competência ou da legalidade. Observou-se que a tentativa de repassar tarefas para a equipe médica ocorria com menor freqüência, sendo mais freqüente solicitar e disputar tarefas que eram consideradas de competência médica.

O trabalho do serviços social foi descrito pela enfermagem como associado à resolução de situações envolvendo alta ou óbito. Já segundo o serviços social, era necessário esclarecimento constante de suas funções e, mesmo assim, "entra residente, sai residente, sempre um vira prá gente e diz: 'Fulana, avisa a família que ele está de alta... Os médicos do staff sabem que isso não é nossa função, mas...'. Isso é estressante!". Os problemas relativos ao aviso de alta às famílias eram causados, em parte, por um descompasso entre a rotina estabelecida e a realidade enfrentada. De acordo com o prescrito, as altas deveriam ser informadas pela secretaria das enfermarias com 24 horas de antecedência ao setor de internação e alta, que então avisaria à família para que viesse buscar o paciente. Mas, com a escassez de leitos, era consenso entre médicos que eles deveriam ser liberados assim que um paciente melhorasse, 
para que outro, que estivesse na emergência, pudesse por sua vez liberar o espaço para o próximo caso grave. Assim, se pela manhã o médico encontrasse uma melhora no paciente, seria desejável que ele desocupasse o leito no mesmo dia, o que era incompatível com o longo caminho que a informação deveria percorrer para chegar à família. $O$ serviços social descreveu assim suas atividades no setor: "a gente atende o paciente no leito, atende a família, vê em que a doença interfere, os problemas que vêm de casa e estão interferindo no tratamento, o próprio problema de saúde do paciente interferindo no contexto familiar, como o chefe de família que para de produzir... surgem problemas, você é intermediador".

Entre os enfermeiros e o serviços social ocorriam conflitos relativos aos direitos do paciente, atribuídos pelo segundo à "falta de comunicação na equipe". Foi citado o direito dos adolescentes a ter acompanhantes. O acompanhante era autorizado para menores de 14 anos. Com o novo Estatuto dos Direitos da Criança e do Adolescente, o serviços social argumentou pelo direito até 17 anos, mas percebeu resistência frente ao que seria "interferência": "Até ela [a enfermeira] entender, ela vai dizer 'não, aqui quem manda sou eu', aí fica uma confusão".

Os técnicos de laboratório também mantinham contato com o setor, colhendo materiais e entregando resultados. De acordo com a enfermagem, o técnico, ao entregar sangue para transfusão, deveria "instalar o equipo e pegar a veia do paciente com um escalpo apropriado [de maior calibre]", não fornecido às enfermarias. Muitas vezes o técnico levava a bolsa de sangue, mas não "pegava a veia"; a enfermagem tentava fazê-lo com o material de que dispunha; assim "a veia entope a toda hora, o paciente sofre mais e a enfermagem trabalha dobrado". Ocorria também, de acordo com os depoimentos, que o técnico do laboratório pusesse o sangue para correr num acesso que antes recebia soro e, "como o calibre não era apropriado, entupia tudo".

A comunicação era uma fonte constante de problemas. Existiam queixas da nutrição quanto à falta de informação acerca de exames que exigiriam preparos relativos à alimentação, transferência de pacientes de um leito para outro sem que o setor fosse avisado ("a comida vai trocada"), altas e admissões não informadas. Os fluxos de informações eram muito precários, gerando queixas generalizadas e confusões diversas. A grande fragmentação das atividades contribuía para dificultar a gerência das informações. Os procedimentos de complementação diagnóstica nem sempre eram informados à enfermagem; ocorriam transferências de paciente (de leito, enfermaria ou andar) sobre as quais a enfermagem não sabia informar. Os médicos passavam, entravam e saiam, muitas vezes sem ter dado bom dia a qualquer um que não pertencesse à sua própria equipe.

A fragmentação do trabalho gera monotonia. Na pesquisa realizada acerca do sofrimento psíquico (Rego, 1993), foi encontrado que $24,4 \%$ do pessoal considerava que as tarefas que realizava eram sempre as mesmas, sendo esse o grupo com maior freqüência de sofrimento psíquico (35,1\%). A fragmentação era justificada como respeito à autonomia de cada categoria profissional ou por uma pretendida liberação da enfermagem de algumas tarefas, como na passagem para secretárias e maqueiros. Nesse caso, a suposta solução, que parcela e desqualifica o trabalho, gera outras tarefas tais como recolocar soros em "veias entupidas" durante o deslocamento do paciente.

Outro exemplo de fragmentação é o caminho prescrito de um exame, desde o seu pedido até o retorno do resultado ao médico: o médico decidia, o interno fazia o pedido num formulário próprio e o colocava numa caixa; a secretária recolhia os formulários, protocolava os pedidos, entregava-os aos setores correspondentes (radiologia, laboratório, ultra-som etc.). Esses setores registravam as solicitações e mandavam o formulário de volta com marcação de horários, frascos necessários, o que fosse indicado a cada caso; a secretária recebia e registrava o recebimento. Mas o caminho do exame não acabava aí. Vejamos o caso de um exame de urina: a secretária recebeu o pedido de volta com o frasco esterilizado; esse frasco deveria ser entregue à enfermagem para que orientasse o paciente quanto ao modo correto de colher o 
material, recolhesse o frasco cheio e o devolvesse à secretária, que deveria repassá-lo ao laboratório. Até chegar o resultado existiam, nas palavras de um médico, "inúmeras possibilidades de erro". No intuito de diminuir o percurso, foi proposto que a secretária entregasse o frasco diretamente ao paciente, mas como ela não poderia orientá-lo para colher corretamente o material, os exames tornavam-se pouco confiáveis. No caso de um exame que exigisse o transporte do paciente teríamos a inclusão do maqueiro; em outros, o técnico do laboratório viria colher o material necessário. Questionado sobre a forma e a instância de determinação dessas rotinas, o médico entrevistado não soube dizer quem as determinava. Certamente a chefia da divisão médica assinava ordens de serviço sobre as rotinas, mas não necessariamente teria planejado todos os seus pontos. A organização do trabalho semelhante à da fábrica entra no hospital como se fosse naturalmente a melhor forma de atingir os fins propostos.

Para exemplificar um caso em que o trabalho real reduz a fragmentação, pode-se apresentar a rotina de encaminhamento de um paciente ao serviços social, no prédio anexo: "[para] receber um parente menor [criança] fora da enfermaria: a gente teria que acionar a enfermagem, a enfermagem acionar o maqueiro, dizer para trazer o paciente à sala do serviços social e ele traria o paciente; só que isso não acontece. Então a assistente social também faz esse serviço, vai lá, pega o paciente, traz o paciente, deixa aqui com a família. A assistente social não solicita porque acha que a enfermagem não dá conta".

O comentário aborrecido do serviços social e outros é que "as rotinas existem para serem descumpridas". Vários relatos apontam esse fato como gerador de atritos e de maior carga de trabalho para alguns. Vejamos algumas situações já relatadas: as rotinas de comunicação de altas são ignoradas e a secretaria não avisa às famílias; os técnicos de laboratório põem o sangue com escalpes de calibre inadequado para "aproveitar a veia" ou deixam o serviço para a enfermagem; os médicos, precisando do leito para nova internação, não consideram o prazo prescrito de 24 horas; os médicos plantonistas não permanecem no setor; os enfermeiros, por falta de tempo, não acompanham a visita médica aos pacientes.

Observa-se uma enorme distância entre o prescrito e o real, com conseqüências que variam a cada caso. Mas, quando o prescrito não responde às necessidades do momento, $\mathrm{o}$ trabalhador inventa uma nova forma. O médico pede diretamente ao colega para "fazer agora a ultra-sonografia que é urgente"; o auxiliar de enfermagem, sem pausas, em 12 horas de trabalho, "voa"; a alta é dada e a família que vem para visitar deve encontrar um meio de levar o paciente para liberar a vaga. A defasagem entre o trabalho real e prescrito gera o sentimento de que falta ordem, ou disciplina. Seria necessário o debate constante para que se pudesse distinguir onde há disfunção, ou falta de prescrição, e onde há flexibilidade indicando capacidade de resolver problemas.

O trabalho hospitalar, como já foi dito acima, exige a participação de várias categorias profissionais numa divisão não apenas técnica, mas também social do trabalho. A assistência ao paciente tem o controle do médico, que define o diagnóstico, a conduta terapêutica, a internação ou a alta. Na maior parte dos hospitais públicos brasileiros, o médico dispõe de canais diversos de participação, formais ou não. Discute casos em reuniões clínicas e influi na definição da organização do trabalho (distribuição dos horários dos médicos pelas diferentes atividades, por exemplo). No hospital observado, ele poderia entrar no gabinete do diretor e discutir desde os rumos do hospital, até a falta de gaze para os curativos na emergência. Já a participação da enfermagem nas decisões é mais restrita. No caso observado, muitas vezes a única decisão a ser tomada pela equipe dizia respeito ao que deixar de fazer frente à falta de pessoal ou material. Na eventualidade de falta grave de pessoal, a chefia decidia o que fazer e remanejava pessoal consultando ou informando aos enfermeiros; os auxiliares apenas recebiam a ordem final. A organização de horários para exames ou quaisquer procedimentos não envolvia a participação dos enfermeiros, o que, segundo a chefia de enfermagem, ocorreria se os enfermeiros acompanhassem as visitas 
médicas. $\mathrm{O}$ enfermeiro da ala feminina acompanhava eventualmente a visita médica, mas na ala masculina a enfermeira considerava que não havia tempo disponível para isso. A participação nas decisões de internação e planejamento de alta era mínima e não havia participação nas reuniões clínicas. Apesar disso, as solicitações dos familiares de informações sobre a situação dos pacientes eram dirigidas à enfermagem, que se defrontava diariamente com a impossibilidade de respondê-las. O plantão noturno se ressentia mais desse alijamento do que o pessoal diurno. Em vários depoimentos, os AEs queixaram-se de desconhecimento em relação à vida do hospital devido à "falta de comunicação". Não existiam reuniões ordinárias de equipes multidisciplinares, e as que reuniam a enfermagem eram caracterizadas por conteúdo normativo.

Há uma concordância geral, aparentemente sustentada por critérios técnicos, de que o trabalho na área é determinado pelo médico, coordenado pelos enfermeiros, executado pelos técnicos e auxiliares de enfermagem. Nenhum grupo, além dos médicos, fez referência a discussões clínicas regulares. Essa organização está naturalizada. As hierarquias são rígidas e relacionadas às divisões por áreas de saber ou categorias profissionais. Foi ouvido de um médico que ele se relaciona com a chefia de enfermagem "de capitão para sargento"; nessa linha de pensamento, os enfermeiros seriam os cabos e os auxiliares, os soldados... E costumase afirmar que soldados não pensam, obedecem! Nas discussões em grupo, essa passagem, incluída no texto de descrição do trabalho, criou reações intensas, sempre de negação; mas os comentários vinham carregados de mágoas. Um enfermeiro observou: "provavelmente esse médico desejaria que fosse assim...". Ao mesmo tempo, ao serem questionados sobre as soluções que poderiam sugerir para diversos problemas, os auxiliares respondiam: "mas se eles, que estudaram, não resolvem...".

A possibilidade de participação está intimamente relacionada com os tempos e os ritmos do trabalho. Para a enfermagem, o tempo é dado pelas rotinas prescritas, pela alta intensidade do trabalho, pela constante "falta de tempo". Essa expressão surgia sempre que sugeríamos uma conversa sobre o trabalho ou a participação na pesquisa; também aparecia ao sugerimos a implantação de reuniões clínicas, específicas ou multidisciplinares. Já para os médicos, os fins de semana e os feriados estão preservados, o tempo é gerido a partir de uma conjugação entre as necessidades dos pacientes assistidos e as possibilidades dos médicos. Embora eles se considerem pressionados pela intensidade do trabalho, suas rotinas são mais flexíveis.

Existe uma clara opção por uma organização do trabalho que reforça quantitativamente o grupo médico e o pessoal de enfermagem de nível médio e elementar. Poucos comentários foram ouvidos quanto à falta de assistentes sociais, de psicólogos, fisioterapeutas e de outros personagens que idealmente fazem parte da equipe. A necessidade de enfermeiros é considerada secundária face à premente necessidade de auxiliares. Os trabalhadores do hospital naturalizam a atual organização, baseada nessas proporções. A divisão do trabalho no hospital é complexa, tanto quando consideramos as diversas categorias profissionais, quanto como na distribuição de tarefas internamente à mesma categoria e entre serviços. Na hierarquia dos serviços, as enfermarias de clínica eram apelidadas a "Coréia", por serem aquinhoadas com o trabalho mais "duro" e menos valorizado.

\section{As cargas psíquicas e cognitivas no trabalho hospitalar}

Uma vez que havia uma encomenda de intervenção nas enfermarias, tendo como ponto de apoio a queixa de "cargas excessivas de trabalho", buscamos delimitar o que os trabalhadores do hospital destacavam como tal, dando relevo às cargas cognitivas e psíquicas. 
Por carga cognitiva, ou mental, entende-se os recursos mentais que o trabalhador deve dedicar à tarefa, ou seja, a quantidade de informações que ele deve considerar na sua realização, seu grau de complexidade, os recursos de memória de que deverá lançar mão, entre outros aspectos. Já a carga psíquica diz respeito aos recursos afetivos, estando relacionados ao sentido atribuído à tarefa e outros aspectos da relação que os trabalhadores, individual e coletivamente, mantém com seu trabalho. O conceito de carga é capaz de "ressaltar na análise do processo de trabalho os elementos deste que interatuam dinamicamente entre si e com o corpo do trabalhador, gerando aqueles processos de adaptação que se traduzem em desgaste, entendido como perda da capacidade potencial e/ou efetiva corporal e psíquica" (Laurell, 1989, p. 110).

Como vimos na descrição do processo e da divisão do trabalho observado, a maior parte das tarefas, em especial as que exigem mais esforço físico e menos preparo técnico, são executadas pelos auxiliares. Eles se queixam de serem pouco ajudados pelos enfermeiros, que reservariam para si as tarefas consideradas menos pesadas. Talvez os enfermeiros estejam expostos a uma menor carga física, mas certamente sua carga psíquica e cognitiva é grande e pouco reconhecida.

O trabalho nas enfermarias exigia percepção e elaboração de informações complexas, em quantidades consideradas excessivas por todos. A intensidade da carga cognitiva depende do número de fontes e freqüência das informações, da sua quantidade e densidade, sendo importante avaliar o tempo atribuído ao processamento de cada informação até o recebimento da próxima. Se a informação é muito breve exige maior atenção e memória. Quando o tempo é limitado deve-se evitar passar muitas informações de uma só vez. Nas enfermarias, em especial no período da manhã, o tempo era sempre insuficiente e as informações, muitas. Estas deveriam ser anotadas nos prontuários, livros de plantão e outros documentos. Por falta de tempo, as anotações se acumulavam e, se feitas, adiante não eram lidas.

De acordo com Neffa (1988), a comunicação pode ser perturbada pelas condições do meio ambiente, pela multiplicidade de funções dos trabalhadores envolvidos e pela inadequação do tempo reservado a receber e processar a informação.

Além das cargas cognitivas, havia uma sobrecarga psíquica advinda do reconhecimento da impossibilidade de atender às demandas.

Dissemos acima que o trabalho da enfermagem era, em parte, aliviado pela existência de acompanhantes para os pacientes mais graves. Mas isso gerava sobrecarga devido à ansiedade e à necessidade de atenção trazida pelos acompanhantes. Num plantão noturno, um auxiliar foi interrompido diversas vezes durante o preparo da medicação para atender a chamados de acompanhantes. $\mathrm{O}$ auxiliar deve então avaliar a gravidade da situação, decidir se deve chamar o médico plantonista, e, se for o caso, chamá-lo. Essas interrupções propiciam erros tais como a troca de medicação, duplicação ou falta de algum item, risco agravado pela intensidade do trabalho e pela falta de significado decorrente do parcelamento da atividade.

A adoção de decisões é um dos componentes da carga de trabalho. Nas entrevistas ficou evidente que essa equipe, em especial os enfermeiros, toma decisões a cada passo do trabalho, algumas vezes sem disporem de todas as informações necessárias, ou de suporte organizacional adequado. O enfermeiro relata assim a rotina da noite: "Assim como falta enfermagem, falta médico de especialidade; o residente de uma especialidade fica inseguro com a outra. Se o residente ficar inseguro, você tem que decidir; ele volta pro repouso e você fica com o doente". "Num caso de decidir se troca ou não uma sonda vesical, o médico pode dizer que você contaminou o paciente, mas ele está sangrando, entupiu, você tem que liderar e tomar uma posição. Não dá para esperar o dia seguinte". Na ausência ou insuficiência de enfermeiros, a decisão acaba por ficar a cargo dos auxiliares: "vocês dizem aqui [no texto de descrição das atividades] que o grau de influência dos auxiliares é mínimo; não é tão mínimo assim não, eles ficam sozinhos na 
ala aos sábados, domingos, feriados, quando temos apenas um enfermeiro por andar; eles detectam problemas, solicitam o médico, questionam prescrições médicas; mesmo pela rotina ele não é um mero executor, tem uma formação, tem obrigação de saber o que está fazendo".

As relações com usuários constituem freqüentemente um requerimento do posto de trabalho para quem o ocupa (Neffa, 1988). Nas atividades em que, pela pouca dotação de pessoal, formam-se filas de espera, a proliferação de queixas e reclamações por parte de pessoas com graves dificuldades provoca, entre os que os atendem, ora estados depressivos, ora uma certa agressividade. Essa manifestação dos efeitos da carga psíquica é mais freqüente entre os trabalhadores a quem se atribui a função de "barreira" entre grupos diversos (Neffa, 1988, p. 113). Identifica-se no hospital o papel de barreira na enfermagem e uma situação típica é o contato com acompanhantes e visitas. Os auxiliares, em especial, ficam expostos a um grande número de demandas e queixas, podendo responder muito pouco. Os familiares buscavam na enfermagem ouvintes para queixas, soluções para problemas, esclarecimentos sobre a evolução do paciente etc.; como a maior parte das demandas não podia ser atendida pelos auxiliares, e nem mesmo pelo enfermeiro, eles ficavam impacientes, queixando-se da ansiedade das famílias. A resposta mais comum era "procure o médico pela manhã", que era considerada adequada pelos demais profissionais. Além de informações, os visitantes solicitavam a troca de lençóis, de soro, o fornecimento de água para beber, remédios, abertura ou impedimento ao ingresso de outros. A enfermagem evitava deixar qualquer procedimento relativo aos pacientes para esse horário. Evitava, por um lado, incomodar os visitantes ou permitir interferências em tarefas de cunho técnico. Por outro lado, esse era um momento de pausa, sempre interrompida pelas solicitações de pacientes, acompanhantes e visitas.

As cargas psíquicas estão fortemente relacionadas ao conteúdo do trabalho e às (im)possibilidades de atribuir a ele um sentido positivo. No hospital, lida-se com a vida e a morte. O trabalho é freqüentemente qualificado como uma missão, o cuidar permitindo sentir-se importante socialmente e para cada paciente. Além da falta de tempo para registrar e ler informações, as más condições dos equipamentos (por exemplo, as camas sem grades), a falta de medicamentos e os aspectos impeditivos provenientes da organização do trabalho, tais como a farmácia fechada a noite, contribuem para a insatisfação com a qualidade do cuidado prestado.

Mas vários aspectos da vida são ativamente excluídos das relações hospitalares. Como exemplo, mencionamos a sexualidade. Nas anotações de um plantão noturno havia, num certo dia, treze pacientes em uso de medicação ansiolítica. Segundo um depoimento médico, a administração de tranqüilizantes nessa intensidade é habitual na internação hospitalar e tem como objetivo inibir a excitação sexual dos pacientes. Não nos deteremos aqui nas questões relativas às relações com os doentes, mas certamente a subtração desses aspectos da vida humana exige um gasto de energia psíquica por parte dos profissionais envolvidos.

A ansiedade da equipe de enfermagem era visível quando havia a possibilidade de um óbito antes do término do plantão. Essa situação foi observada com a transferência de um paciente do CTI para a clínica médica autorizada, segundo os médicos residentes, por um "acadêmico". A conduta estava sendo considerada inadequada pelos residentes. A enfermagem, com base na experiência, previa que o paciente não resistiria e um AE dizia que eles teriam que "fazer o pacote" (as providências após o óbito), pois nenhuma equipe recebe o plantão sem esse procedimento cumprido, o que atrasaria sua saída. Enquanto aguardava a decisão dos médicos, a enfermagem comentava os transtornos práticos que uma morte causaria, bem como o sentimento de pesar daí advindo. Só houve alívio quando o paciente retornou ao CTI.

A atividade cognitiva dos trabalhadores dá lugar a um saber produtivo, um conhecimento prático, geralmente de natureza coletiva, que pode amenizar a carga de trabalho mental (Neffa, 1988). Os trabalhadores da enfermagem afirmam que após a 
passagem pela "Coréia" são capazes de trabalhar em qualquer setor no hospital. Amenizam a afirmativa excluindo o centro cirúrgico. Por outro lado, pessoas deslocadas de outros setores para compensar faltas "não dão conta" das exigências.

Enfim, identificamos que as cargas são muitas, estreitamente relacionadas à organização do trabalho, freqüentemente cargas físicas e psíquicas, confirmando a adequação das queixas à realidade e ao conhecimento teórico.

As tentativas de amenizar tais cargas referiam-se ao repasse de tarefas indesejadas para grupos menos qualificados. Boa parte das resistências são tecidas como defesas corporativas, sem que tenham sido observadas experiências de compartilhamento multiprofissional de decisões, tarefas ou mesmo de espaços.

\section{Comentários finais}

O hospital estudado vive paralisias que se nos afiguram estruturais. A organização do trabalho, que fragmenta as tarefas e os trabalhadores, reafirma as características da subjetividade moderna, individualista (ou corporativa) e competitiva que atravessam a rede de relações no hospital. Produzir mudanças nesse cenário é algo difícil, mas necessário a fim de permitir que o trabalho aí realizado possa ser desenvolvido, ampliando suas possibilidades de trabalho em equipe e seu sentido de cuidado do outro.

Certamente podemos falar numa ética ligada ao "bom atendimento do paciente", noção que ora prioriza a ciência e a técnica, ora o tratamento humano, atencioso, capaz de dar suporte às angústias e às dores do doente e de sua família. Mas as estratégias adotadas pelos próprios trabalhadores para fazer frente à sobrecarga, repassando tarefas pesadas para quem tem menos poder, evitando o enfrentamento de tudo que possa ser postergado - como controlar o "sumiço" dos lençóis ou ler o livro de ocorrências - acabam por prejudicar essa possibilidade de atribuição de sentido e prazer no trabalho. Essas estratégias são de alto custo psíquico e não colaboram em nada para a formação de equipes coesas nem para a produção de novos modos de atuar.

Sem ignorar as dificuldades de transporte ou de múltiplos empregos (não discutidas no escopo deste trabalho), podemos pensar nos freqüentes atrasos como um exemplo de "solução" para o cansaço adotada individualmente e parcialmente suportada pelas equipes de uma mesma categoria - lembremos o misto de irritação e compreensão dos colegas frente aos atrasos. Nesses atrasos: evidencia-se a valorização insuficiente do aspecto coletivo da tarefa de "passagem do plantão", momento raro em que está prescrita a discussão dos casos por profissionais não médicos, possibilitando a distribuição negociada das tarefas. Com os atrasos, colegas são obrigados a permanecer mais horas, ao fim de plantões já longos, por vezes atrasando-se para outros compromissos. Um outro exemplo de estratégia de defesa está nas "escapadas" do espaço de trabalho, nem sempre negociadas.

Como vimos, são muitos os depoimentos de falta de comunicação no hospital. A cooperação entre os grupos já foi maior, hoje ela é percebida mais freqüentemente dentro de uma mesma categoria. Ocorre também a cooperação - ou pelo menos a manifestação de preocupação - atravessada pelas relações pessoais, por sentimentos de coleguismo construídos por longo tempo de trabalho no mesmo plantão. Em serviços como o estudado, essa forma de construção de solidariedade é prejudicada pela maior rotatividade do pessoal, bem como pelo caráter de castigo que a lotação na chamada "Coréia" pode assumir. As atitudes de cuidado com os colegas existem, como no caso de um trabalhador fazer sua refeição mais rapidamente para liberar um colega, ou mesmo não faltar, ainda que indisposto, para não sobrecarregar os 
demais. Mas estas atitudes se mesclam com sentimentos de injustiça frente à ausência de soluções institucionais para os problemas. Essas estratégias de redução de cargas são ora compreendidas como inevitáveis, ora deflagradoras de reações de irritação entre colegas, que pedem regras claras e punições para os transgressores. As estratégias de gestão não se baseavam na produção de melhores formas de organização coletiva do trabalho, mas em formas de pressão individualizada, como aquela da "folga-prêmio" para os que jamais faltam ou se licenciam.

A divisão do trabalho observada, mais clara e menos flexível no serviço de enfermagem, cria problemas e insatisfações. A idéia de "trabalhar coeso" era vista como ideal poucas vezes atingido. Os diversos segmentos que integravam a força de trabalho no setor exerciam tarefas interligadas com a enfermagem, porém a fragmentação do trabalho dificultava a percepção da totalidade do processo. Os enfermeiros reconhecem que a fragmentação tem sido origem de diversas confusões. No entanto, não surge da equipe mais do que a queixa de uma situação a que parece estar "grudada". A organização naturalizada do trabalho não tem sido posta em questão. A estratégia, acima descrita, de passar aos menos qualificados parte das tarefas é compatível com a estratégia governamental de terceirização das atividades consideradas estranhas à finalidade do hospital. As empresas terceirizadas são contratadas, em geral, para os serviços de limpeza e de alimentação e vão se estendendo no fornecimento de trabalhadores para postos administrativos e para outros mais próximos da assistência, como o dos responsáveis pelo transporte interno de pacientes.

No cotidiano, as limitações salariais são pouco comentadas, são mais freqüentes as referências às condições gerais de trabalho, às relações intra ou inter-equipes, às relações com os pacientes e suas famílias, aos sentimentos que essas condições e relações suscitam.

Em nossa pesquisa deparamo-nos com a dificuldade de produzir momentos de reflexão coletiva sobre o trabalho, tendo adotado como caminho possível o que chamamos de "grupos-relâmpago". A concentração em alguns poucos do esforço por produzir melhores condições de trabalho (expressa na queixa de que "são sempre os mesmos que participam") acaba por gerar cansaço e ressentimento.

A prática corrente, especialmente visível na enfermagem, de tomada centralizada de decisões gera reações ambíguas: reclama-se da impropriedade dessa falta de participação coletiva, mas não há nenhum movimento no sentido de ampliação rotineira da participação, sendo os chamados nesse sentido considerados como propostas de aumento da carga de trabalho já excessiva.

Tentativas de produzir cooperação interdisciplinar ou interprofissional são recebidas com reserva, tendendo a prevalecer a atitude defensiva de cada um naquilo que tradicionalmente lhe cabe. A chamada "equipe multidisciplinar" é palco de disputas corporativas de toda ordem, numa tentativa de saída do mal estar pela estratégia do "cada um por si”. O pouco espaço de participação nas decisões relativas à assistência aos pacientes é disputado dentro de uma organização do trabalho que não permite nenhuma elasticidade. As decisões de ordem geral se dão num espaço-tempo que se espalha fora e dentro do hospital, que também são atravessadas pelas características dos corporativismos e dos interesses privados de diversas ordens. Intervir nesse campo exigiria dos profissionais um alto nível de organização e de clareza de objetivos.

O trabalho que originou o que aqui está relatado foi interrompido antes que a devolução de seus resultados pudesse ser feita de modo satisfatório, principalmente em função de mudanças na direção do hospital, com a conseqüente modificação de prioridades e desmonte da equipe que constituía o Núcleo de Saúde do Trabalhador, apoio indispensável para a face de intervenção que o projeto pretendia desenvolver. A dissertação originada (Osorio, 1994) foi entregue aos trabalhadores, mas isso não pode ser, de modo algum, considerado suficiente. Este artigo poderá, talvez, constituir-se num dispositivo a mais, ainda 
que insuficiente, que pode contribuir para movimentos de transformação que eram desejados e ensejaram a demanda que iniciou a pesquisa.

\section{Referências}

Araújo, G. M. (1992). Contribuição para a prática de inspeção sanitária no setor de saúde a partir das atividades desenvolvidas no Hospital Geral de Jacarepaguá. Monografia, Especialização em Saúde Pública, Escola Nacional de Saúde Pública, Fundação Oswaldo Cruz, Rio de Janeiro.

Brito, J. C. de (1991) Procurando compreender os conceitos de carga, trabalho e risco (tecnológico). Revista Brasileira de Saúde Ocupacional, 72 (19), 38-40.

Chauí, M. (1993). Conformismo e resistência. São Paulo: Brasiliense.

Chauí, M. (1982). Cultura e democracia: o discurso competente e outras falas. São Paulo: Moderna.

Laurell, A. C. \& Noriega, M. (1989). Processo de produção e saúde. São Paulo: Hucitec.

Leplat, J. \& Hoc J.-M., (1983). Tâche et activité dans l'analyse psychologique des situations, Cahiers de psychologie cognitive, 3 (1), 49-63.

Neffa, J. C. (1988). Que son las condiciones y medio ambiente de trabajo? Propuesta de una nueva perspectiva. Buenos Aires: Humanitas.

Osorio-da-Silva, C. (1994). Curar adoecendo: um estudo do processo de trabalho hospitalar em busca da inventividade e da vida. Dissertação de Mestrado, Escola Nacional de Saúde Pública, Fundação Oswaldo Cruz, Rio de Janeiro.

Pitta, A. M. F. (1989). Trabalho hospitalar e sofrimento psíquico. Tese de doutorado, Faculdade de Medicina, Universidade de São Paulo, São Paulo.

Rego, M. P. da C. e M. de A. (1993). Trabalho hospitalar e saúde mental: o caso de um hospital geral e público no município do Rio de Janeiro. Dissertação de Mestrado, Instituto de Medicina Social, Universidade do Estado do Rio de Janeiro, Rio de Janeiro.

Santos, M. L. (1995). O trabalho dos anjos de branco: um estudo em hospital geral público. Dissertação de Mestrado, Coordenação dos Programas de Pós-Graduação de Engenharia, Universidade Federal do Rio de Janeiro, Rio de Janeiro.

Endereço para correspondência: claudiaosorio@terra.com.br 